\title{
POMEN PROMETA ZA OBLIKOVANJE PROSTORA IN REGIJE
}

\author{
Jani Kozina, univ. dipl. geograf \\ Geografski inštitut Antona Melika ZRC SAZU, Gosposka ulica I3, \\ SI-I000 Ljubljana, Slovenija. \\ e-mail: jani.kozina@zrc-sazu.si
}

Izvirni znanstveni članek

COBISS 1.01

\section{Izvleček}

V prispevku je predstavljen pomen prometa za oblikovanje prostora in regije kot ene najbolj značilnih prostorskih struktur na zemeljskem površju. Medtem ko smo po teoretičnem konceptualiziranju prometa kot dejavnika oblikovanja prostora preverili njegov pomen za oblikovanje prostorskega razvoja Slovenije, smo s teoretičnega vidika enako naredili tudi za regijo in s praktičnega vidika za osrednjeslovensko regijo.

Ključne besede: promet, prostor, regija, regionalna identiteta, geografija prometa, osrednjeslovenska regija, Slovenija

\section{THE MEANING OF TRANSPORT FOR SHAPING SPACE AND REGION}

\begin{abstract}
The paper presents the meaning of transport for shaping space and region as one of the most significant spatial structures on the Earth's surface. After the theoretical conceptualization of transport as a factor for shaping space and verifying of its importance for the shaping of spatial development of Slovenia, in theory we did the same for region and from a practical point of view for the Central Slovenian region.
\end{abstract}

Key words: transport, space, region, regional identity, transport geography, osrednjeslovenska region, Slovenia 


\section{UVOD}

Promet je ena bistvenih sestavin geografskega okolja, zato je že od vsega začetka geografske znanosti predmet njenega intenzivnega preučevanja. Promet predstavlja prenos ljudi, blaga, energije in informacij iz kraja v kraj. Torej omogoča njihovo prostorsko porazdelitev in vnaša dinamiko materialnemu in nematerialnemu svetu na zemeljskem površju. Številni pojavi in procesi v geografski stvarnosti so v takšnem ali drugačnem razmerju s prometom. Njegov pomen se zaradi številnih funkcij, ki jih opravlja, povečuje. Po besedah Vrišerja (1978) zato nekateri zgodovinarji upravičeno menijo, da je bila prometna revolucija, to je vrsta iznajdb in izboljšav v prometni tehniki in organizaciji v 19. in 20. st., enakovredna industrijski revoluciji in da je skorajda $v$ enaki meri prispevala k povečanju družbeno-gospodarskega blagostanja.

Povezanost prometa s prostorom je večplastna. Geografijo prometa pri tem zanima predvsem, kako je bila izbira prometne poti pogojena s fizičnimi dejavniki prostora, kako so prebivalci premagovali probleme fizičnega okolja pri gradnji prometne infrastrukture in kakšen je vpliv prometa na prostor (Černe 1991). Svojstvene slovenske prostorske razmere so posledica geografskega položaja Slovenije v Srednji Evropi, na stiku naravnih, gospodarskih in kulturnih enot, na pomembnem političnogeografskem, prometnem, gospodarskem in kulturnem prehodnem evropskem območju (Černe in Jeršič 1998). Skozi vso zgodovino so bile čez naše ozemlje speljane številne poti, ki so povezovale različne dele Evrope. Do danes se to stanje ni kaj dosti spremenilo. Še več, Slovenija v današnjem skupnem političnem in gospodarskem prostoru Evropske unije predstavlja pomembno križišče V. in X. evropskega prometnega koridorja. Prehodnost je v prometnem smislu temeljna lastnost našega ozemlja. Tokovi blaga, ljudi, energije in informacij imajo zato toliko večji vpliv na oblikovanje prostora in prostorskih struktur Slovenije.

Namen prispevka je preučiti pomen prometa za oblikovanje prostora in regije kot ene najbolj značilnih prostorskih struktur na zemeljskem površju. Medtem ko smo po teoretičnem konceptualiziranju prometa kot dejavnika oblikovanja prostora preverili njegov pomen za oblikovanje prostorskega razvoja Slovenije, smo s teoretičnega vidika enako naredili tudi za regijo. S praktičnega vidika pa smo spoznanja teoretičnih izpeljav o vplivih prometa na oblikovanje regije poizkušali aplicirati na primeru osrednjeslovenske regije, ki ima $\mathrm{v}$ slovenskem prostoru glede na različne kriterije, tudi prometne, najbolj središčen položaj.

\section{PROMET KOT DEJAVNIK OBLIKOVANJA PROSTORA}

Raziskovanja vplivov prometa na prostor so se s pomočjo klasičnih lokacijskih teorij med prvimi lotili nemški geografi in ekonomisti von Thünen, Weber in Christaller (Kagermeier 2000). Vsi na takšen ali drugačen način omenjajo promet oziroma prometno dostopnost kot temeljni lokacijski dejavnik pri razmeščanju različnih krajev, območij in dejavnosti. Z njegovo pomočjo poizkušajo pojasniti ustroj ali organizacijo prostora. Njihovi pristopi so bili kasneje s strani različnih avtorjev klasičnih in neoklasičnih lokacijskih teorij (Palander, Hoover, Lösch, Greenhut, Isard idr.) sicer deležni številnih dopolnitev, vendar so povečini vsi upoštevali promet, oziroma njegove izpeljanke kot sta dostopnost in prometni stroški, kot 
temeljni lokacijski dejavnik. Po ugotovitvah Kušarja (2008) je promet lokacijski dejavnik, ki se je do sedaj najpogosteje preučeval. To kaže na izredno zanimanje raziskovalcev za preučevanje razmerij na relaciji promet-prostor in $\mathrm{z}$ določenega vidika že $\mathrm{v}$ startu potrjuje osnovno hipotezo o njuni tesni medsebojni povezanosti.

Dejstvo je, da promet kot del prostora vpliva nanj na nešteto načinov (Knowles 2006). V literaturi so znani številni primeri preučevanja te povezanosti, ki dokazujejo vplive prometa na razmestitev gospodarstva, strukturo trgovine in narodno blagostanje (Behrens in sod. 2007), vrednost zemljišč (Cohen in Morrison Paul 2007), rast delovnih mest (Nared 2007), aktivnost trga s kmetijskimi in gozdnimi zemljišči (Lisec in Lobnik 2007), koncentracijo poselitve (Kozina 2008), prostorski razvoj (Papadaskalopoulos in sod. 2005) itd.

Kljub naštetim in še mnogim drugim empiričnim dokazom pa naj bi se vloga prometa kot lokacijskega dejavnika s sodobnim vsestransko razvitim prometnim omrežjem v razvitih državah zmanjšala (Vrišer 2000). Skladno s konceptom prostorsko-časovne konvergence po Janellovi (1968) so se razdalje med kraji in območji pod vplivom modernih tehnologij v prometu v zadnjih 200 letih skrčile na minimum. Z vzpostavljanjem informacijske družbe in novih komunikacijskih tehnologij (mobilni telefon, internet) naj bi bil po mnenju Shawa (2006) temeljitih dopolnitev potreben celo do sedaj splošno uveljavljeni (konvencionalni) koncept prostorsko-časovnih odnosov. Prostoru in prometu naj bi se na ta način zmanjševala funkcija, vloga in pomen.

Kibernetični prostor je vsekakor objektivnost, ki se vzporedno in na podoben način kot fizični prostor v vesolju širi v vse pore družbeno-gospodarskega življenja na Zemlji. Na pomenu čedalje bolj pridobivajo novi brezprostorski socialni odnosi, ki v določenih ozirih zmanjšujejo pomen prostora in posledično tudi prometa.

Na tem mestu se samo po sebi postavlja vprašanje, v kolikšni meri promet še opravlja svojo funkcijo oblikovalca prostora. Knowles (2006) trdi, da promet še vedno pomembno vpliva na oblikovanje prostorskih vzorcev razvoja, kot glavni argument pa navaja v luči sedanjega časa prostorsko neenakomerno razporejeno časovno-prostorsko konvergenco. Pomena prometa za oblikovanje prostora se ne da zanikati tudi zaradi obsega prometnih gibanj, ki stalno naraščajo (Banister 2005), kljub vzporednemu širjenju kibernetičnega prostora. Pričakujemo lahko, da se bodo prostorski učinki prometa v prihodnosti še stopnjevali. Poleg družbenih in gospodarskih vplivov pa se bodo ob sedanjih prometnih trendih verjetno še najbolj okrepili okoljski, med katerimi v nasprotju s prvima dvema skupinama prevladujejo tisti z negativnim predznakom.

\section{PROMET IN PROSTORSKI RAZVOJ SLOVENIJE}

Promet je že stoletja pomemben dejavnik oblikovanja slovenskega prostora. Območje, kjer danes prebivamo Slovenci, leži namreč na stiku velikih evropskih makroregij, pomembnih prometnih povezav in razpotij (Melik 1935). Na samo $20.256 \mathrm{~km}^{2}$ ozemlja, kolikor ga obsega Slovenija, se stikajo kar štiri evropske makroregije (Alpe, Panonska kotlina, Dinarsko gorstvo in Sredozemlje), čezenj pa prek Postojnskih vrat (612 m n.v.) poteka najnižji in najlažji prehod v 1500 km dolgi gorski verigi Alpe-Dinarsko gorstvo med Sredozemljem ter Srednjo in Vzhodno Evropo (Gams 1998). Posledično se ne gre čuditi, da so čez naše ozemlje že od pradavnine pa do danes potekale številne pomembne prometne poti, ki so v prostoru pustile svoje pečat. 
V agrarni dobi promet ni imel tako velikega pomena kot v kasnejših obdobjih. Razloga sta predvsem v slabših prometnih povezavah in prevladujočem življenjskem slogu, ki se je v povezavi s samooskrbnim kmetijstvom omejeval predvsem na domače okolje. Posledica je bila zelo nizka mobilnost prebivalstva ter razpršena poselitev in gospodarstvo. Promet je imel v tedanjem času zlasti funkcijo trgovskega povezovanja mest in trgov (Klemenčič 2003; 2005). Zaradi teh dejavnikov je bil regionalno-prostorski razvoj vse do polovice 19. st. skladen in enakomeren. Slovenski prostor je bil opremljen z dovolj gostim omrežjem centralnih naselij, s tržnimi, administrativnimi in prometnimi središči za potrebe regij in celo z vplivi na širšo okolico (Žagar 1978).

Pomen prometa za prostor in vse sfere družbeno-gospodarskega življenja se je izrazito spremenil v industrijski dobi. Tehnološki razvoj je z izboljševanjem in gradnjo sodobnejših oblik prometnic ter modernejšimi prevoznimi načini poskrbel za nove oblike mobilnosti, ki jih je po drugi strani zahteval tudi točkasti (industrijski) gospodarski razvoj. Največji prelom v razvoju prometa, ki je imel številne prostorske posledice in je postal temeljni kamen današnjega prostorskega razvoja Slovenije, je bila izgradnja južne železnice v sredini 19. st. Za to obdobje je na eni strani značilen hiter razvoj mest, trgov in ostalih naselij vzdolž železniške proge, po drugi strani pa gospodarsko nazadovanje celih pokrajin, ruralizacija prejšnjih centralnih naselij, povečana agrarna gostota, proletarizacija kmetijskega gospodarstva ipd. (Žagar 1978). Od tega obdobja dalje je za Slovenijo značilen neskladen regionalni razvoj in bipolarizacija prostora na razvita ter manj razvita območja. Z nadaljnjo izgradnjo železniškega omrežja in modernizacijo cestnega omrežja so se vzpostavili pogoji za tektonske premike v regionalno-prostorski strukturi Slovenije.

Izgradnja prometne infrastrukture je vplivala na večjo stopnjo medsebojne povezanosti in prometne dostopnosti. Z intenzivno motorizacijo v drugi polovici 20 . st. se je med drugim močno povečala in razširila dnevna migracija zaposlenih, okrepila so se centralna naselja in zvečala se je dostopnost za prebivalce iz bolj odmaknjenih in hribovitih predelov. Kljub temu je prihajalo do obsežnega bega prebivalstva v ravninska območja in kraje z večjim številom delovnih mest. Industrijska in urbana središča vzdolž glavnih prometnic so v Sloveniji izoblikovali tako imenovani 'industrijski polmesec', prostorsko koncentracijo urbanizacije in industrije, kateri se je prilagodil tudi tako imenovani 'prometni križ' (Černe in Jeršič 1998).

Za železnico, ki so jo med drugim od Dunaja do Trsta s tehnologijo 19. st. zgradili v pičlih šestnajstih letih, je izgradnja avtocestnega omrežja drugi največji infrastrukturni projekt pri nas, ki se izvaja že od leta 1972. Avtocestni križ je v minulem obdobju še bolj vplival na časovno-prostorsko konvergenco, z nadaljnjo koncentracijo gospodarstva in poselitve ob svojih koridorjih pa poskrbel za dodatno povečevanje regionalnih razvojnih razlik. Po mnenju mnogih avtorjev (Vrišer 1999; Kušar 2005; Horvat 2006) so razlike v prometni dostopnosti med deli slovenskega ozemlja eden glavnih dejavnikov za nastanek manj razvitih območij. Kljub temu pa sta po mnenju Černeta in Jeršiča (1998) ravno dobra razvitost cestnega omrežja in visoka stopnja motorizacije pomenili tudi enega od temeljev za zasnovo policentričnega urbanega in prostorskega razvoja, ki naj bi zagotavljal enakomernejši regionalni razvoj. Podobno, samo v obratnem vrstnem redu, razmišlja tudi Drozg (2005), ki meni, da je namen policentrizma danes med drugim zlasti v vzpostavljanju približno enake dostopnosti do storitvenih dejavnosti in družbene infrastrukture za vse prebivalce Slovenije. Slednje je med 
drugim tudi eden od pomembnejših poudarkov državnih strateških prostorskih dokumentov, ki opredeljujejo bodoče značilnosti prostorskega in prometnega razvoja Slovenije (Kozina 2009).

\section{PROMET KOT DEJAVNIK OBLIKOVANJA REGIJE}

Regija je eden izmed temeljnih geografskih pojmov, kljub temu pa je njegova vsebina po mnenju številnih avtorjev zelo nejasna. Pomen in razumevanje koncepta regije sta se spreminjala, kakor se je spreminjalo razumevanje in opisovanje sveta v družbeni geografiji (Sagan 2004). Povsem vsakdanji in na široko uporabljan termin v sebi skriva številna dojemanja, zaradi katerih si strokovna javnost ni povsem enotna. Po Klemenčiču (2005) noben drug pojem ni obsojen na tako različna, pogosto celo kontroverzna razumevanja. Podobnega mnenja je tudi Vrišer (2002), ki v Uvodu v geografijo, enem izmed temeljnih geografskih del trdi, da se pojem regije v geografski literaturi tolmači precej raznoliko. Z njim se strinja tudi Drozg (2004), ki pravi, da je opredeljevanje regij zelo diskutabilno in nedorečeno, ter da je njegova vsebina odvisna od zornega kota gledanja. Iz tega je moč povzeti, da enoznačna in splošno sprejeta definicija regije (na žalost) ne obstaja. Ugotovitev Černeta (1991), da je vloga prometa pri opredeljevanju regije in njenih značilnosti pogosto odrinjena na rob kot zadnji del poglavja o določeni regiji, tako po vsem tem ne more biti nobeno razočaranje. Vsekakor pa odkrivanje teh razmerij po mnenju Keelinga (2008) predstavlja velik izziv za raziskovalce. Po njegovih navedbah pretekle raziskave v prometu zagotavljajo dovolj velik nabor znanj o možnostih prihodnjega družbenega in prostorskega razvoja, medtem ko obstaja potreba po razvoju novih teorij in metod za podrobnejšo osvetlitev socialnih vidikov dostopnosti in mobilnosti na regionalni ravni.

Raziskovanje vplivov prometa na regijo ni možno brez dobrega definiranja obeh pojmov. Medtem ko je pri prometu slika v osnovi jasna, za regijo tega vsekakor ne moremo trditi. Bistvu regije se je $\mathrm{z}$ vidika teoretičnega konceptualiziranja $\mathrm{v}$ zadnjem obdobju v svetovni literaturi verjetno še najbolj približal Paasi, ki v osrčje njenega opredeljevanja postavlja identiteto (Paasi 1986). Načelo soodvisnega delovanja različnih geografskih dejavnikov, ki ga mnoge definicije regije navajajo brez natančnejše nadaljnje obrazložitve, naj bi po Paasiju rezultiralo v oblikovanje regionalne identitete, kar naj bi regiji zagotavljalo z vseh strani tako opevano individualnost, specifičnost oziroma enkratnost. Regionalna identiteta je v osnovi oblika kategorizacije, kjer se meje uporabljajo za razlikovanje enega območja družbene kolektivnosti od drugega (Paasi 2002), pri njenem formiranju pa naj bi bile bistvenega pomena komunikacije kot sredstvo obvladovanja ljudi oziroma oblikovanja njihove zavesti (Paasi 1986).

Komunikacije, ki jih v tem kontekstu mirno lahko povezujemo/enačimo s termini, kot so promet/prometnice/dostopnost, imajo po Paasiju torej odločilen pomen za oblikovanje regionalne identitete in posledično za oblikovanje regije. S tovrstno izpeljavo se strinja tudi Klemenčič (2005), ki povezuje nove premike v krepitvi družbeno-gospodarske moči in s tem identitete na regionalni ravni pri nas z najnovejšim razvojem prometne infrastrukture in krepitvijo regionalnih središč. Po njegovem mnenju med dejavnike oblikovanja prostorskih enot, kamor sodi tudi regija, poleg gospodarskega, urbanega in demografskega razvoja 
spada še razvoj prometne infrastrukture. Regionalna središča s svojo močjo in prometno dostopnostjo določajo meje vplivnega (gravitacijskega) območja. Na ta način se oblikujejo območja skupnega življenja kot prizorišča, kjer odnos med človekom in okoljem oblikuje določen časovno-prostorski specifični način življenja. Skladno s temi ugotovitvami lahko pritrdimo mnenju Černeta (1991), da promet s svojimi funkcijami v prostoru omogoča interakcijo med kraji in območji, oziroma na ta način ustvarja regije in jih med seboj povezuje.

Teoretične izpeljave kažejo na jasen pomen prometa pri oblikovanju regije. Njihovo veljavnost pa lahko preverimo samo v praksi. V nadaljevanju predstavljamo konkreten poskus opredelitve pomena prometa za oblikovanje osrednjeslovenske regije, da preverimo, ali zgoraj navedena teoretična dognanja veljajo tudi v realnem svetu. V osredju zanimanja so bili predvsem vplivi prometa na obseg regije, ki poleg notranje strukture predstavlja bistveno prostorsko sestavino vsake regije.

\section{POMEN PROMETA ZA OBLIKOVANJE OSREDNJE- SLOVENSKE REGIJE}

Po Paasiju (1986) je regija živ organizem, ki se stalno razvija. Njeno odkrivanje zato ni nikoli zaključen proces. Dokaze za to nam nudi pogled v preteklost oziroma zgodovino, ki je po mnenju Gilbertove (1988) neobhodno metodološko orodje za regionalne raziskave. V začetku te diskusije moremo zato reči le, da s pojmom osrednjeslovenska regija mislimo na regijo, ki ima središče v Ljubljani. Posledično bi ji lahko nadeli tudi ime ljubljanska regija, vendar se v luči obravnavane (prostorske) tematike raje naslonimo na poimenovanje, ki hkrati tudi nepoznavalcu razmer že samo po sebi sporoča določene prostorske značilnosti regije. Pri tem pa je treba opozoriti, da izraza osrednjeslovenska regija ne smemo zamenjevati s terminom Osrednjeslovenska (statistična) regija. V prvem primeru gre namreč za geografsko regijo, katere obseg se ves čas spreminja, medtem ko gre v drugem primeru za, vsaj kar se obsega tiče, povsem določeno prostorsko entiteto administrativnega značaja.

\section{I. Obseg osrednjeslovenske regije v preteklosti}

Tako kot pri vseh drugih regijah se je obseg osrednjeslovenske regije skozi zgodovino spreminjal. Določeno obliko je verjetno imela že v predantični dobi, zagotovo pa so bile meje znane in širše zastavljene v rimskem času. Središče regije je bila tedaj Emona, prednica današnje Ljubljane in pomembna vojaška, trgovska ter prometna postojanka Rimljanov. S propadom rimskega cesarstva, porušitvijo Emone in preseljevanjem narodov v 6. st. je regionalno-prostorski razvoj osrednjeslovenske regije izgubil dotedanjo kontinuiteto. Nov zagon je doživel z oblikovanjem dežel v srednjem veku, kar je pustilo močne vidne in nevidne sledi v prostoru in družbi vse do današnjih dni. Bistvenega pomena pri tem je pojav zavesti oziroma občutka deželne pripadnosti. Razlikovanje med Štajerci, Gorenjci, Notranjci, Primorci, Korošci in Dolenjci je še danes živo prisotno v slovenski družbi.

$\mathrm{V}$ času avstro-ogrske monarhije je bila Ljubljana središče Kranjske. Njene meje so večinoma potekale po gorskih slemenih (razvodje med jadranskim in črnomorskim povodjem, Karavanke) in po Savi (Piry in Orožen Adamič 1998). Več kot očitno so se torej oprle 
na fizičnogeografske elemente prostora, ki tudi v prometnem smislu predstavljajo težko prehodne ovire. V začetku je bila zavest, biti Kranjec, zelo močno zakoreninjena v tedanji družbi, sčasoma pa se je bolj okrepila regionalna identiteta na nižji regionalni ravni med Gorenjci, Dolenjci in Notranjci. Danes tako izraza Kranjska in Kranjci uporabljamo samo še v oziru na nekdanjo habsburško kronsko deželo, medtem ko so (nekdanje) deželne meje in zavest pripadnosti Gorenjski, Dolenjski in Notranjski marsikje še vedno zelo žive. Tovrsten razvoj oziroma oblikovanje osrednjeslovenske regije je značilno za agrarno dobo, ko so bile meje med vaškimi skupnostmi, med mestom in podeželjem, med posestvi zemljiških gospodov, med upravnimi enotami itd. jasne (Klemenčič 2005).

\subsection{Obseg osrednjeslovenske regije v novejšem času}

$\mathrm{Z}$ industrijsko revolucijo so prej lahko prepoznavne meje fizičnega okolja začele bledeti. Ljubljana je od tedaj dalje svoj pomen v prostoru in regiji povečevala na račun velikosti gravitacijskega območja in posebnega (upravno-prometnega) položaja. Gravitacijski vidik je postal nosilec regionalno-prostorskega razvoja, pa tudi krepilec in oblikovalec lokalne/ regionalne identitete (Klemenčič 2005). Meje osrednjeslovenske regije so se oblikovale v skladu z razmerji 'moči' Ljubljane do ostalih regionalnih središč in kakovostjo prometnih povezav v njenem zaledju. Po gravitacijski enačbi je namreč sila gravitacije med dvema središčema $\mathrm{v}$ premem sorazmerju $\mathrm{z}$ njuno močjo in $\mathrm{v}$ obratnem sorazmerju s kvadratom njune medsebojne oddaljenosti (Kozina in Plevnik 2009).

V skladu s temi ugotovitvami bi pričakovali določeno stopnjo ujemanja meja regije po kriterijih gravitacije, regionalne identitete in prometne dostopnosti. S tega vidika se nam zdi zanimiva primerjava dveh raziskav, ki sta določali mejo osrednjeslovenske regije $\mathrm{z}$ vidika prometne dostopnosti občin do Ljubljane kot najhitreje dostopnega regionalnega središča (slika 1) in z vidika pripadnosti prebivalcev domači pokrajini (slika 2).

V prvem primeru se je prometna dostopnost določala na podlagi analiz modela prometne dostopnosti, kjer je bila vsaka občina dodeljena regionalnemu središču, do katerega z osebnim avtomobilom po cestnem omrežju Republike Slovenije najhitreje dostopa večinski delež občinskega prebivalstva (Kozina 2008). V drugem primeru pa se je pripadnost prebivalcev domači pokrajini ugotavljala na podlagi anketnega vprašalnika, kjer so morali anketiranci začrtati obseg domače pokrajine (Klemenčič 2002). Rezultati te študije so sintezno nekoliko bolje predstavljeni v članku Regija in regionalna struktura Slovenije (Klemenčič 2005).

Primerjava rezultatov obeh študij prikazuje zelo zanimive geografske razsežnosti. Na prvi pogled sicer težko govorimo o kakršnemkoli detajlnem ujemanju meja. Povsem natančne skladnosti niti ne gre pričakovati, saj je občutek pripadnosti domači pokrajini element regionalne identitete in po Paasiju (2003) proces, ki se večinoma oblikuje skozi daljša časovna obdobja. Prometna dostopnost pa je element prostora, ki se z izgradnjo samo ene nove prometnice lahko $\mathrm{v}$ hipu spremeni. Kljub temu je z natančnejšo analizo možno priti do precej pomenljivih spoznanj. Primerjava obeh vrst meja kaže na njihovo sorazmerno dobro ujemanje v severnem, zahodnem in jugozahodnem delu regije, medtem ko je slabše ujemanje značilno zlasti za vzhodni in južni del regije. 
Slika 1: Obseg osrednjeslovenske regije glede na prometno dostopnost občin do Ljubljane kot najhitreje dostopnega regionalnega središča

Figure 1: The scale of Central Slovenian region according to transport accessibility of the municipalities to Ljubljana as the most accessible regional center

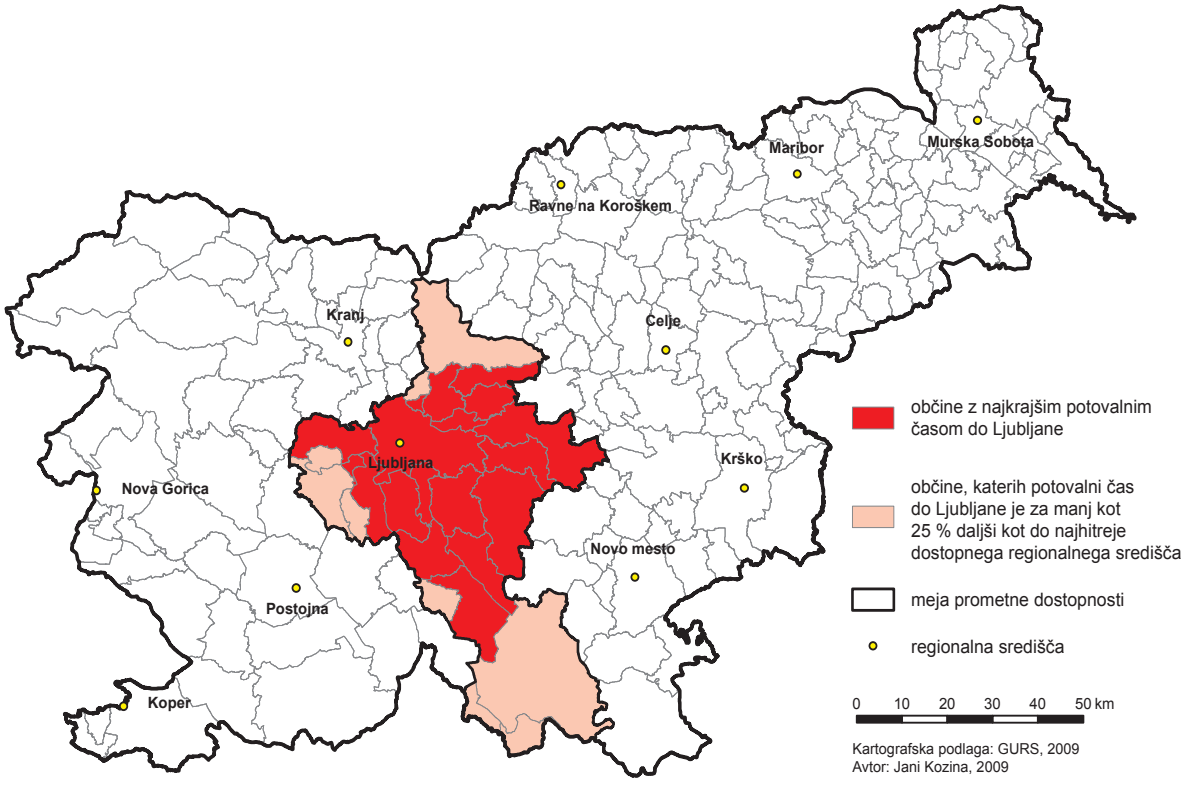

Vir/source: Kozina 2008

Odstopanja v obsegu vzhodnega dela meje so posledica metodološkega neskladja raziskav. Študija o pripadnosti prebivalcev domači pokrajini je med regionalnimi središči upoštevala tudi Trbovlje, ki ga je raziskava o prometni dostopnosti izpustila. Posledično kakršnegakoli (ne)ujemanja meja v tem delu regije ni mogoče komentirati, saj bi bila slika ob enakovredni (ne)vključenosti Trbovelj v obeh raziskavah najverjetneje drugačna.

Nekoliko specifična pa je situacija na jugu regije, kjer je ribniško-kočevsko območje po predstavah ljudi razpeto med Novim mestom in Postojno, čeprav bi po kriteriju prometne dostopnosti in predvsem gravitaciji veliko bolj sodilo pod Ljubljano. Neskladje si razlagamo predvsem $\mathrm{z}$ najverjetneje nekoliko slabšo prostorsko razporeditvijo vzorca anketiranih $\mathrm{v}$ tem delu Slovenije. Ribniško-kočevsko območje je namreč območje s specifično lokalno identiteto. Povsem mogoče je, da imajo ‘pravi’ Notranjci ali Dolenjci prebivalce tega območja za svoje, vendar bi se s tem verjetno strinjal le majhen odstotek Ribn'čanov in Kočevcev.

Na območjih boljšega ujemanja obeh vrst meja je zelo zanimivo spremljati potek starih prometnih povezav, ki jih v eni od svojih monografij o Sloveniji omenja Melik (1959). Najbolj izrazita med njimi je cestna povezava po Črnem grabnu mimo Trojan, ki so stoletja dolgo predstavljale mejo med Štajersko in Kranjsko. Na tem prelazu danes še vedno poteka meja med pripadnostjo prebivalcev Ljubljani in Celju oziroma Štajerski, tako kot tu poteka meja v prometni dostopnosti med obema omenjenima središčema. 
Slika 2: Obseg osrednjeslovenske regije po predstavah ljudi

Figure 2: The scale of Central Slovenian region according to the people's perception

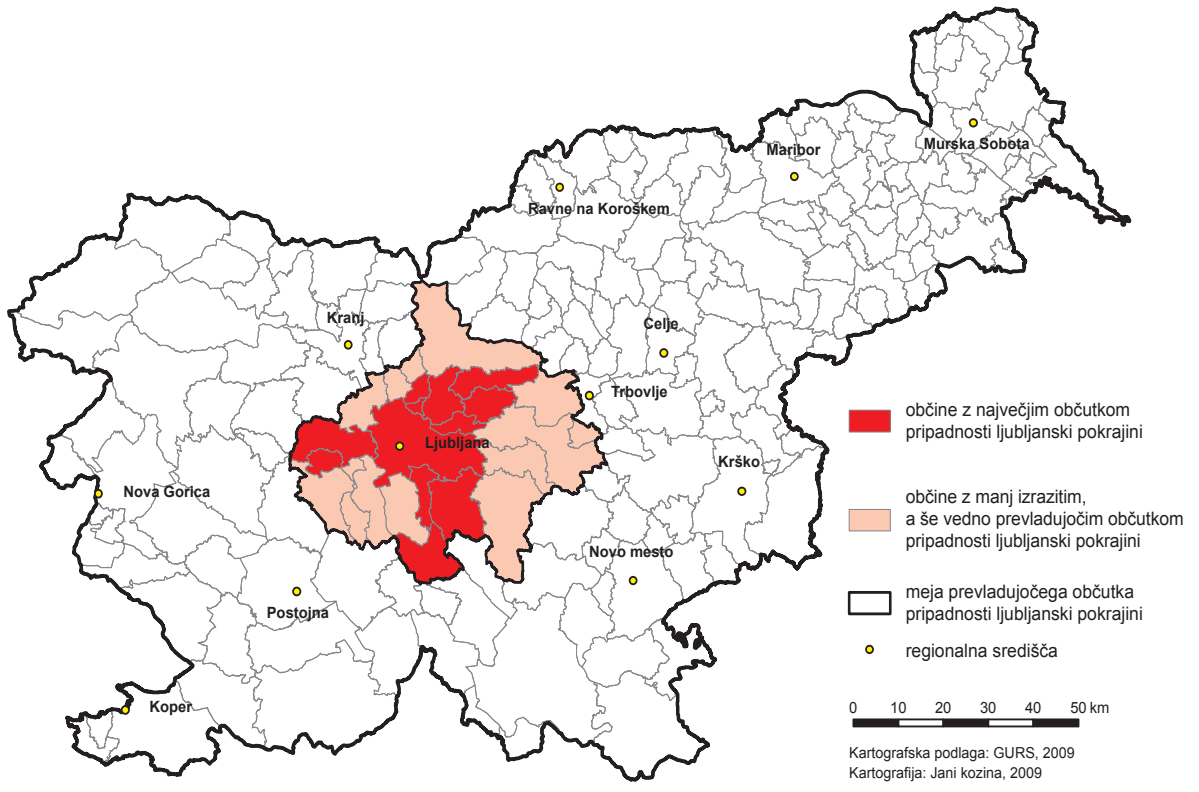

Vir/source: povzeto po Klemenčič 2005

Druga taka povezava se kaže mimo lučinske suhe doline, ki povezuje Horjul in Gorenjo vas v Poljanski dolini. Po Melikovih besedah je ta dolina nekoč kazala 'veliki prehod' od Ljubljane prek Horjula in Poljanske doline k Cerknemu in dalje čez Šentviško goro k Tolminu ter skozi Čedad na ravnino v Furlaniji. Danes del te doline leži v skrajnem zahodnem območju občine Dobrova-Polhov Gradec, ki hkrati označuje skrajne zahodne meje osrednjeslovenske regije tako glede pokrajinske pripadnosti prebivalcev kot po kriteriju prometne dostopnosti.

Sklenemo lahko, da je potek meja v obeh raziskavah razmeroma identičen v liniji od Trojan prek občine Kamnik in severnega obmestja Ljubljane do skrajno zahodne občine DobrovaPolhov Gradec ter naprej prek južnega obrobja Ljubljanskega barja vse do Velikolaščanske pokrajine, ki meji na ribniško-kočevsko območje. Meje se torej dokaj solidno ujemajo povsod, kjer je njihova primerjava z metodološkega vidika možna, edina večja izjema pri tem pa je že prej omenjeno specifično ribniško-kočevsko območje. Prikazani primer na ta način zelo ilustrativno prikazuje, da določena mera povezanosti med prometom in obsegom regije nedvomno obstaja. Pri tem pa je treba še enkrat poudariti, da regionalnega zavedanja oziroma občutka pripadnosti domači pokrajini ne smemo enačiti z regionalno identiteto, čeprav predstavlja njen zelo pomemben del. Ugotovljena razmerja torej ne odsevajo v celoti vplivov prometa na oblikovanje regionalne identitete, ki je temeljni pokazatelj neke regije. Prav tako pa se je treba zavedati, da promet ni edini dejavnik, ki vpliva na oblikovanje občutka pripadnosti in posledično na oblikovanje regionalne identitete ter s tem obsega regije. 


\section{SKLEP}

Prikazane vsebine nazorno dokazujejo, da je promet nedvomno pomemben oblikovalec prostora. Nekoliko odprto sicer ostaja vprašanje razmerja med prostorom in kibernetičnim prostorom, ki nastaja zaradi vpeljave modernih komunikacijskih sistemov. Pojav slednjega namreč $\mathrm{v}$ določeni meri zagotovo zmanjšuje pomen prometa $\mathrm{v}$ prostoru. Kljub nekaterim razmeroma jasnim protiargumentom različnih avtorjev, pa bodo na tem področju zagotovo potrebne bolj poglobljene raziskave, ki ne bodo temeljile le na logičnem skladanju splošno sprejetih in znanih dejstev.

Podobno kot marsikje drugod so značilnosti slovenskega prostora s svojo lego in prehodnostjo omogočale prometu v preteklosti razmeroma velike povratne vplive. Razvoj prometne infrastrukture $v$ industrijski dobi in v novejšem obdobju je povzročil reorganizacijo prostorskega razvoja. Promet je razdelil prostor na razvita in manj razvita območja, zato je ena bistvenih nalog današnjega regionalnega in prostorskega planiranja izboljševanje prometne dostopnosti območij, ki so jih glavne prometne osi obšle. S tem se bodo marsikje obnovile družbene in gospodarske moči, kar bo prispevalo k skupnemu doseganju skladnejšega regionalnega razvoja.

Promet ima poleg vplivov na prostor pomemben pomen tudi pri oblikovanju regije. V teoriji in praksi smo dokazali, da nedvomno obstaja povezava med prometom in regionalno identiteto kot temeljnim kazalcem določevanja obsega in obstoja regij. Promet skrbi za izmenjavo stikov med prebivalci posameznih območij, s čimer se krepi skupna zavest, ki z drugimi dejavniki lahko pripelje do oblikovanja regije - osrednje prostorske enote geografskega preučevanja. V luči novejšega razvoja informacijske družbe pa bodo tudi na tem področju v prihodnosti potrebne nadaljnje raziskave, ki bodo poglobljeno orisale razmerja med vsebinami pojmov kot so gravitacija, prometna dostopnost in regionalna identiteta.

\section{Viri in literatura}

Banister, D. 2005: Unsustainable transport: city transport in the new century. New York. Behrens, K., Lamorgese, A. R., Ottaviano, G. I. P., Tabuchi, T. 2007: Changes in transport and non-transport costs: local vs. global impacts in a spatial network. Regional science and urban economics 37, 625-648. Amsterdam.

Cohen, J. P., Morrison Paul, C. J. 2007: The impact of transportation infrastructure on property values: a higher-order spatial econometrics approach. Journal of regional science 47, 3, 457-478. Amherst.

Černe, A. 1991: Geografija prometa - metode in tehnike. Ljubljana.

Černe, A., Jeršič, M. 1998: Promet: cestni, železniški in pomorski promet ter plinovodno omrežje. V: Gams, I., Vrišer, I. (ur.) Geografija Slovenije. Ljubljana.

Drozg, V. 2004: Regija - kontekst ali koncept spoznavanja pokrajine. V: Drozg, V. (ur.): Teorija in praksa regionalizacije Slovenije. Maribor.

Drozg, V. 2005: Koncepti policentrične ureditve Slovenije. Dela 24, 147-158. Ljubljana.

Gams, I. 1998: Lega Slovenije v Evropi in med njenimi makroregijami. V: Gams, I., Vrišer, I. (ur.) Geografija Slovenije. Ljubljana. 
Gilbert, A. 1988: The new regional geography in English and French-speaking countries. Progress in human geography 12, 2, 208-228. London.

Horvat, A. (ur.) 2006: Resolucija o nacionalnih razvojnih projektih za obdobje 2007-2023. Ljubljana.

Janelle, D. G. 1968: Central place development in a time-space framework. Professional geographer 20, 5-10. Hamilton.

Kagermeier, A. 2000: German research in transport geography: life in the space between objective analysis and political advice. GeoJournal 50, 1, 17-24. Dordrecht, Boston, London.

Keeling, D. J. 2008: Transportation geography - new regional mobilities. Progress in human geography 32, 2, 275-283. London.

Klemenčič, M. M. 2002: Miselna slika pokrajin. V: Spoznavni zemljevid Slovenije. Ljubljana.

Klemenčič, M. M. 2003: Civilizacijske razvojne stopnje in razvojni problemi obrobnih območij v Sloveniji. Dela 19, 153-164. Ljubljana.

Klemenčič, M. M. 2005: Regija in regionalna struktura Slovenije. Dela 23, 5-58. Ljubljana.

Knowles, R. D. 2006: Transport shaping space: differential collapse in time-space. Journal of transport geography 14, 6, 407-425. New York.

Kozina, J. 2008: Prometna dostopnost kot kriterij regionalizacije Slovenije. Diplomsko delo. Oddelek za geografijo, Filozofska fakulteta Univerze v Ljubljani. Ljubljana.

Kozina, J., Plevnik, A. 2009: Prometna dostopnost in regionalizacija Slovenije. V: Pomurje: trajnostni regionalni razvoj ob reki Muri. Murska Sobota.

Kozina, J. 2009: Vloga prometne dostopnosti v strateških prostorskih dokumentih Slovenije. V: Razvojni izzivi Slovenije. Ljubljana.

Kušar, S. 2005: Manj razvita območja kot element politike skladnejšega regionalnega razvoja v Sloveniji: pretekle izkušnje in prihodnji izzivi. Dela 24, 113-124. Ljubljana.

Kušar, S. 2008: Vloga prostorskega planiranja pri lociranju proizvodnih dejavnosti v Sloveniji. Doktorska disertacija. Oddelek za geografijo, Filozofska fakulteta Univerze v Ljubljani. Ljubljana.

Lisec, A., Lobnik, F. 2007: Trg in tržna vrednost kmetijskih zemljišč v Sloveniji. V: Razvojni izzivi Slovenije. Ljubljana.

Melik, A. 1935: Slovenija: geografski opis. Ljubljana.

Melik, A. 1959: Posavska Slovenija. Ljubljana.

Nared, J. 2007: Model razporeditve pričakovnih delovnih mest kot instrument za načrtovanje in vrednotenje projektov: primer resolucije o nacionalnih razvojnih projektih za obdobje 2007-2013. V: Razvojni izzivi Slovenije. Ljubljana.

Papadaskalopoulos, A., Karaganis, A., Christofakis, M. 2005: The spatial impacts of EU Pan-European axes: city clusters formation in the Balkan area and developmental perspectives. Transport policy 12, 488-499. Oxford.

Paasi, A. 1986: The institutionalization of regions: a theoretical framework for understanding the emergence of regions and the constitution of regional identity. Fennia 164, 1, 108-146. Helsinki. 
Paasi, A. 2002: Bounded spaces in the mobile world: deconstructing 'regional identity'. Tijdschrift voor economische en sociale geografie 93, 2, 137-148. Amsterdam.

Paasi, A. 2003: Region and place: regional identity in question. Progress in human geography 27, 4, 475-485. London.

Piry, I., Orožen Adamič, M. 1998: Upravna razdelitev. V: Geografski atlas Slovenije. Ljubljana.

Sagan, I. 2004: Looking for the nature of the contemporary region. Progress in human geography 28, 2, 141-144. London.

Shaw, S.-L. 2006: What about 'time' in transportation geography? Journal of transport geography 14, 237-240. Oxford.

Vrišer, I. 1978: Regionalno planiranje. Ljubljana.

Vrišer, I. 1999: Regionalni razvoj slovenskih pokrajin in občin. IB - revija za planiranje 33, 2-3, 47-67. Ljubljana.

Vrišer, I. 2000: Industrijska geografija. Ljubljana.

Vrišer, I. 2002: Uvod v geografijo. Ljubljana.

Žagar, M. 1978: Vloga prometa pri razvoju ruralne pokrajine. Geographica Slovenica 6, 29-33. Ljubljana.

\section{THE MEANING OF TRANSPORT FOR SHAPING SPACE AND REGION}

\section{Summary}

The paper presents the meaning of transport for shaping space and region as one of the most significant spatial structures on the Earth's surface. After the theoretical conceptualizing of transport as a factor for shaping space and verifying of its importance for the shaping of spatial development of Slovenia, in theory we did the same for region and from a practical point of view for the Central Slovenian region.

The shown contents evidently prove that transport undoubtedly is an important designer of the space. Otherwise remains somewhat an open question of the relationship between space and cyber space, which arose from the introduction of modern communication systems. The emergence of the latter, to some extent, certainly reduces the importance of transport in space. Despite some relatively clear counterarguments of different authors, in this field more in-depth research will certainly be needed, which will not be based solely on composing the generally accepted logic and known facts.

Characteristics of the Slovenian territory with its location and the transition enabled a relatively large feedback effects to transport in the past. Development of transport infrastructure in the industrial era and the recent period has led to a reorganization of the spatial development. Transport divided space to the developed and less developed areas. That is why it is crucial for today's regional and spatial planning to improve transport accessibility to areas that have been bypassed by the main transport axes. This will restore many social and economic powers, which will have its own contribution to the overall achievement of balanced regional development. 
Transport also has an important impact in shaping the region. In theory and practice, we have shown that between transport and regional identity as a fundamental indicator for determining the extent and existence of the region is certainly there. The role of transport is to exchange the links between residents of different places, thus reinforcing the common consciousness, which, together with other factors could lead to the development of the region the central spatial unit of the geographical research. In light of recent developments of information society further research will be needed, which will make a detailed outline of the relationship between the content of term such as gravity, transport accessibility and regional identity.

(Translated by the author) 